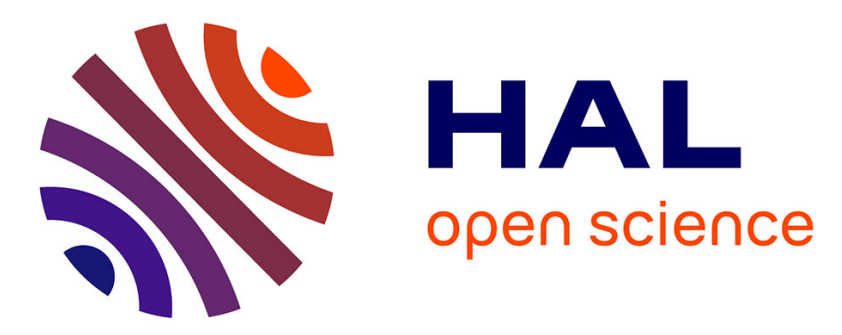

\title{
Quantifying perpendicular magnetic anisotropy at the Fe-MgO(001) interface
}

Charles-Henri Lambert, A. Rajanikanth, Thomas Hauet, Stéphane Mangin, E. E. Fullerton, Stéphane Andrieu

\section{- To cite this version:}

Charles-Henri Lambert, A. Rajanikanth, Thomas Hauet, Stéphane Mangin, E. E. Fullerton, et al.. Quantifying perpendicular magnetic anisotropy at the $\mathrm{Fe}-\mathrm{MgO}(001)$ interface. Applied Physics Letters, 2013, 102 (12), pp.122410. 10.1063/1.4798291 . hal-01276614

\section{HAL Id: hal-01276614 https://hal.science/hal-01276614}

Submitted on 13 Jul 2016

HAL is a multi-disciplinary open access archive for the deposit and dissemination of scientific research documents, whether they are published or not. The documents may come from teaching and research institutions in France or abroad, or from public or private research centers.
L'archive ouverte pluridisciplinaire HAL, est destinée au dépôt et à la diffusion de documents scientifiques de niveau recherche, publiés ou non, émanant des établissements d'enseignement et de recherche français ou étrangers, des laboratoires publics ou privés. 


\section{AIP Appiled Physics Letters}

\section{Quantifying perpendicular magnetic anisotropy at the $\mathrm{Fe}-\mathrm{MgO}(001)$ interface}

C.-H. Lambert, A. Rajanikanth, T. Hauet, S. Mangin, E. E. Fullerton et al.

Citation: Appl. Phys. Lett. 102, 122410 (2013); doi: 10.1063/1.4798291

View online: http://dx.doi.org/10.1063/1.4798291

View Table of Contents: http://apl.aip.org/resource/1/APPLAB/v102/i12

Published by the American Institute of Physics.

Additional information on Appl. Phys. Lett.

Journal Homepage: http://apl.aip.org/

Journal Information: http://apl.aip.org/about/about_the_journal

Top downloads: http://apl.aip.org/features/most_downloaded

Information for Authors: http://apl.aip.org/authors

\section{ADVERTISEMENT}

\section{AIP Applied Physics Letters}

\section{EXPLORE WHAT'S NEW IN APL}

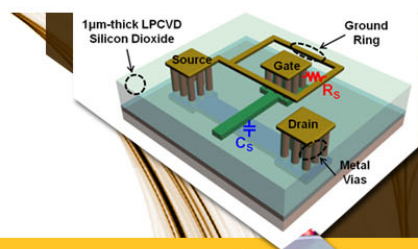

SURFACES AND INTERFACES

Focusing on physical, chemical, biological structural, optical, magnetic and electrical properties of surfaces and interfaces, and more.. 


\title{
Quantifying perpendicular magnetic anisotropy at the $\mathrm{Fe}-\mathrm{MgO}(001)$ interface
}

\author{
C.-H. Lambert, ${ }^{1,2}$ A. Rajanikanth, ${ }^{1}$ T. Hauet, ${ }^{1}$ S. Mangin, ${ }^{1}$ E. E. Fullerton, ${ }^{2}$ \\ and S. Andrieu ${ }^{1, \text { a) }}$ \\ ${ }_{1}^{1}$ Institut Jean Lamour, UMR CNRS 7198, Université de Lorraine, 54506 Vandoeuvre lès Nancy, France \\ ${ }^{2}$ Center of Magnetic Recording Research, University of California, San Diego, California 92093-0401, USA
}

(Received 13 January 2013; accepted 11 March 2013; published online 29 March 2013)

\begin{abstract}
We show that $\mathrm{Fe}-\mathrm{MgO}$ interfaces possess strong perpendicular magnetic anisotropy of $1.0 \pm$ $0.1 \mathrm{erg} / \mathrm{cm}^{2}$ in fully epitaxial $\mathrm{MgO} / \mathrm{V} / \mathrm{Fe} / \mathrm{MgO}(001)$ and $\mathrm{MgO} / \mathrm{Cr} / \mathrm{Fe} / \mathrm{MgO}(001)$ heterostructures. The sign and amplitude of the total anisotropy are quantified as a function of $\mathrm{Fe}$ thickness using magnetometry and ferromagnetic resonance. There is a transition from out-of-plane to in-plane anisotropy for $6 \mathrm{Fe}$ monolayers in $\mathrm{V} / \mathrm{Fe} / \mathrm{MgO}$ and only 4 monolayers in $\mathrm{Cr} / \mathrm{Fe} / \mathrm{MgO}$. A detailed study of the $\mathrm{Fe}$ magnetization and effective anisotropy in both systems explains this difference and quantifies the $\mathrm{Fe}-\mathrm{MgO}$ interface anisotropy. (C) 2013 American Institute of Physics.

[http://dx.doi.org/10.1063/1.4798291]
\end{abstract}

The implementation of films with perpendicular magnetic anisotropy (PMA) enables a broad range of magnetic nanotechnologies. PMA materials have been implemented in hard disk drives for more than a decade delaying the onset of the superparamagnetic limit and are also the basis for prototype bit-patterned media. ${ }^{1}$ There is current interest in integrating PMA materials into spin transfer torque magnetic random access memory (STT-MRAM) as PMA materials provide a pathway to low critical current and high thermal stability. $^{2}$

Perpendicular STT-MRAM devices need to combine large tunnel magnetoresistance (TMR) to read the information and large spin torque efficiency to switch magnetization with a polarised current. This has been largely achieved through the discovery of PMA in $\mathrm{CoFeB} / \mathrm{MgO} / \mathrm{CoFeB}$ magnetic tunnel junctions. ${ }^{3-7}$ It has further been shown that the PMA can be tuned by the application of a voltage.$^{8-12}$ Theoretical analyses highlight different possible mechanism that would lead to PMA and generally involves band hybridization, spin-orbit coupling splitting or strain. ${ }^{13-15}$ Particularly, Yang et al. attributed the PMA to a combination of two factors: overlap between $\mathrm{O}-\mathrm{pz}$ and transition metal $\mathrm{dz}^{2}$ orbitals, as well as degeneracy lift of out-of-plane $3 \mathrm{~d}$ orbitals induced by spinorbit coupling. ${ }^{14}$ In addition, $\mathrm{He}$ and Chen have shown that the lattice mismatch between $\mathrm{MgO}$ and $\mathrm{FeCo}$ could also induce an additional PMA. ${ }^{15}$ Predicted PMA amplitudes can reach $1.46 \mathrm{erg} / \mathrm{cm}^{2}$ in Ref. 14 and $1.9 \mathrm{erg} / \mathrm{cm}^{2}$ in Ref. 15 per $\mathrm{Fe}-\mathrm{MgO}$ interface. Such values are more than 2 times larger than the value obtained for other interface-induced PMA like in $\mathrm{Co} / \mathrm{Pd}, \mathrm{Co} / \mathrm{Pt}, \mathrm{Fe} / \mathrm{Ag}, \mathrm{Fe} / \mathrm{Au}$, or $\mathrm{Co} / \mathrm{Ni}{ }^{16}$

Many recent experimental reports deal with tuning PMA and demonstrating the role of $\mathrm{Fe}_{\mathrm{x}} \mathrm{Co}_{1-\mathrm{x}}-\mathrm{MgO}$ interface. Effect of buffer/cap, inserted $\mathrm{Mg}$ layer, $\mathrm{MgO}$ thickness, $\mathrm{Fe}_{\mathrm{x}} \mathrm{Co}_{1-\mathrm{x}}$ concentration, $\mathrm{CoFeB}$ annealing, ${ }^{3-7}$ and electric charges ${ }^{17,18}$ has been investigated. Besides, similar researches have focused on $\mathrm{Co} / \mathrm{AlO}_{\mathrm{x}}$ interfaces ${ }^{19,20}$ and $\mathrm{FePd} / \mathrm{MgO}{ }^{21}$ Most of these recent experimental results confirm that $\mathrm{Fe}_{\mathrm{x}} \mathrm{Co}_{1-\mathrm{x}} / \mathrm{MgO}$ provides an anisotropy that is perpendicular to the interface.

\footnotetext{
${ }^{\text {a) }}$ Author to whom correspondence should be addressed. Electronic mail: stephane.andrieu@ijl.nancy-universite.fr.
}

However, the amplitude of PMA anisotropy found in the literature shows a large spectrum of PMA amplitude ${ }^{6-9,17,18}$ and the largest values stay much below the theoretical predictions. ${ }^{13-15}$ One could argue that $\mathrm{CoFeB}-\mathrm{MgO}$ interfaces obtained by sputtering exhibit structural defects whereas perfect interfaces are generally assumed in calculations. However even in molecular beam epitaxy (MBE) grown $\mathrm{Au} / \mathrm{Fe} / \mathrm{MgO}$ system, the $\mathrm{Fe} / \mathrm{MgO}$ magnetic anisotropy is found to be much lower than the $\mathrm{Au} / \mathrm{Fe}$ one, i.e., lower than $0.5 \mathrm{erg} / \mathrm{cm}^{2} .5,9,10$

In this letter, we present a careful study of the magnetic features of MBE-grown single-crystal $\mathrm{MgO} / \mathrm{V} / \mathrm{Fe} / \mathrm{MgO}$ (001) and $\mathrm{MgO} / \mathrm{Cr} / \mathrm{Fe} / \mathrm{MgO}(001)$ heterostructures. Magnetization and magnetic anisotropies are measured by different techniques including magneto-optic Kerr effect (MOKE), ferromagnetic resonance (FMR), and magnetometry for Fe thickness ranging from 5 to 12 monoatomic layers (MLs). By considering the contributions of the $\mathrm{Fe}$ magneto-crystalline and shape anisotropies, and the $\mathrm{V}-\mathrm{Fe}, \mathrm{Cr}-\mathrm{Fe}$ and $\mathrm{Fe}-\mathrm{MgO}$ interfaces anisotropies, we can quantify the $\mathrm{Fe}-\mathrm{MgO}$ interface anisotropy and compare to existing experimental and theoretical results.

The samples were grown on single-crystal $\mathrm{MgO}$ (100) substrate using MBE with a base-pressure lower than $10^{-10}$ Torr. The $\mathrm{V}$ or $\mathrm{Cr}$ buffer layers were deposited at room temperature (RT) and then annealed at $600^{\circ} \mathrm{C}$. An Fe wedge was then grown on the $\mathrm{V}$ or $\mathrm{Cr}$ buffer layers and covered with a 6-ML $(1.2 \mathrm{~nm}) \mathrm{MgO}(001)$ film. The typical stacking of a sample is thus $\mathrm{V}$ or $\mathrm{Cr}(10 \mathrm{~nm}) / \mathrm{Fe}\left(\mathrm{t}_{\mathrm{Fe}}\right) / \mathrm{MgO}(1.2 \mathrm{~nm})$ where the Fe thickness $t_{\mathrm{Fe}}$ is varied from 5 to 12 MLs in 1 ML steps. Fe was deposited at RT with no further annealing and capped with $\mathrm{MgO}$ also at RT. The epitaxial relationship, growth mode, number of deposited MLs, and surface flatness were controlled in situ using reflection high energy electron diffraction (RHEED). Figures 1(a) and 1(b) show RHEED intensity oscillations recorded during the growth of $\mathrm{Fe}$ on $\mathrm{Cr}$ and $\mathrm{V}$, respectively. The oscillation period corresponds to $1 \mathrm{ML}$, which allows accurate control of $\mathrm{t}_{\mathrm{Fe}}$ and demonstrates layerby-layer growth and a low surface roughness. The RHEED patterns in the insets confirm the (001) crystalline order for the $\mathrm{Cr}$ and $\mathrm{V}$ buffer layers and $\mathrm{Fe}$ magnetic layers.

Figure 2 shows magnetization curves measured using a Quantum Design SQUID-VSM on both V/Fe(5-7 MLs)/MgO 


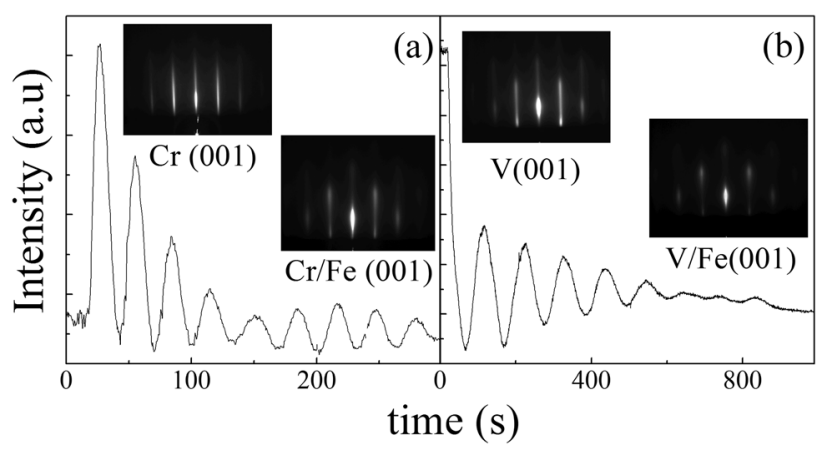

FIG. 1. RHEED intensity oscillations recorded during the growth of Fe on $\mathrm{Cr}(001)$ (a) and V(001) (b), respectively. In inset, RHEED patterns of $\mathrm{V}$ and $\mathrm{Cr}$ (001) buffer layers are shown, as well as $\mathrm{Cr} / \mathrm{Fe}(8 \mathrm{MLs})$ and $\mathrm{V} / \mathrm{Fe}(8 \mathrm{MLs})$.

and $\mathrm{Cr} / \mathrm{Fe}(3-5 \mathrm{MLs}) / \mathrm{MgO}$ systems for both in-plane and outof-plane applied magnetic fields. For the thinnest Fe layers, we observed square out-of-plane loops indicating PMA for the system. For the $\mathrm{V} / \mathrm{Fe} / \mathrm{MgO}(001)$ wedge (Figs. 2(a)-2(c)), the preferential magnetization direction moves from out-ofplane to in-plane as Fe thickness increases from 5 to 7 MLs. In contrast for the $\mathrm{Cr} / \mathrm{Fe} / \mathrm{MgO}(001)$ wedge (Figs. 2(d)-2(f)), this transition occurs for 3-5 ML. Considering that the origin of the PMA in such thin Fe layers is thought to be primarily due to the $\mathrm{Fe}-\mathrm{MgO}$ interface anisotropy, these results clearly show additional contributing factors.

This apparent contradiction results from the difference in the magnetization of the Fe layers in both systems. The measured areal magnetic moment (i.e., M divided by sample area in $\mathrm{erg} / \mathrm{cm}^{2}$ ) should increase linearly with the Fe thickness. If the $\mathrm{Fe}$ atomic moment is the same for all $\mathrm{Fe}$ atoms in the film, the $\mathrm{M}_{\text {/area }}\left(\mathrm{t}_{\mathrm{Fe}}\right)$ should be a straight line passing through 0, with a slope equal to the bulk Fe magnetization (about $1715 \mathrm{emu} / \mathrm{cm}^{3}$ ). It is indeed observed in the $\mathrm{Cr} / \mathrm{Fe} /$ $\mathrm{MgO}$ system (see inset of Fig. 3). This means that the Fe atomic moment is similar in the whole film, and consequently also at the $\mathrm{Cr} / \mathrm{Fe}$ interface. The $\mathrm{V} / \mathrm{Fe} / \mathrm{MgO}$ system does not behave the same way (inset in Fig. 3). If the $\mathrm{M}\left(\mathrm{t}_{\mathrm{Fe}}\right)$ slope in $\mathrm{V} / \mathrm{Fe} / \mathrm{MgO}$ is similar to the slope observed in $\mathrm{Cr} / \mathrm{Fe} /$ $\mathrm{MgO}$ (corresponding to a magnetization of $1680 \pm 50 \mathrm{emu} /$ $\mathrm{cm}^{3}$ which is close to the bulk Fe value), the straight line fit clearly crosses zero for $0.3 \mathrm{~nm}$. Such results suggest that there is a deadlayer thickness $t_{\mathrm{dl}}=0.3 \mathrm{~nm}$ indicating 2 dead magnetic MLs in our $\mathrm{V} / \mathrm{Fe} / \mathrm{MgO}$ samples. This behavior is in fact not surprising since a reduction of Fe magnetization at the interface with $\mathrm{V}$ is known and has been explained by roughness, charge transfer, and anti-parallel polarization of the $\mathrm{V} \cdot{ }^{22,23}$ An oxygen contamination of the starting V(001) surface should also contribute to these magnetic dead layers in Fe grown at RT. ${ }^{24}$

The effective anisotropy constant $\mathrm{K}_{\text {eff }}$ was extracted from the area between the out-of-plane and in-plane loops in one of the hysteresis quadrants. The results are shown in Fig. 3 where we plot the result for the magnetic thickness $\left(t_{\mathrm{Fe}}-t_{\mathrm{dl}}\right)$. We also measured the $\mathrm{V} / \mathrm{Fe} / \mathrm{MgO}$ wedge samples for $\mathrm{t}_{\mathrm{Fe}}$ ranging from 7 to 12 MLs using MOKE and FMR. The FMR measurements used a coplanar waveguide connected to a vector network analyzer to both generate and record the signal. The external DC magnetic field was applied in-plane. Figure 4 shows the typical FMR profiles obtained for in-plane magnetized samples. Shift in the field resonance with in-plane applied field gives access to the effective anisotropy through the relation $\omega_{0}=\gamma\left[\mathrm{H}_{\mathrm{ip}}\left(\mathrm{H}_{\mathrm{ip}}+\mathrm{H}_{\mathrm{Keff}}\right)\right]^{1 / 2}$ where $\omega_{0}$ is the frequency at resonance, $\gamma$ is the magneto-mechanical ratio for an electron spin, $\mathrm{H}_{\mathrm{ip}}$ is the strength of the static applied magnetic field, and $\mathrm{H}_{\mathrm{Keff}}$ is the effective anisotropy field of the sample $\mathrm{H}_{\mathrm{Keff}}=2 \mathrm{~K}_{\mathrm{eff}} / \mathrm{M}_{\mathrm{s}}$ (Ref. 25) (we ignore here the small Fe cubic anisotropy). MOKE experiments were performed with an applied field perpendicular to the sample plane. For all samples, typical hard axis loops were recorded and anisotropy fields were extracted assuming a square in-plane loop. The results for various thicknesses are also shown in Fig. 3.

The values of effective anisotropies $\mathrm{K}_{\text {eff }}$ extracted from SQUID-VSM, FMR, and MOKE experiments are plotted in
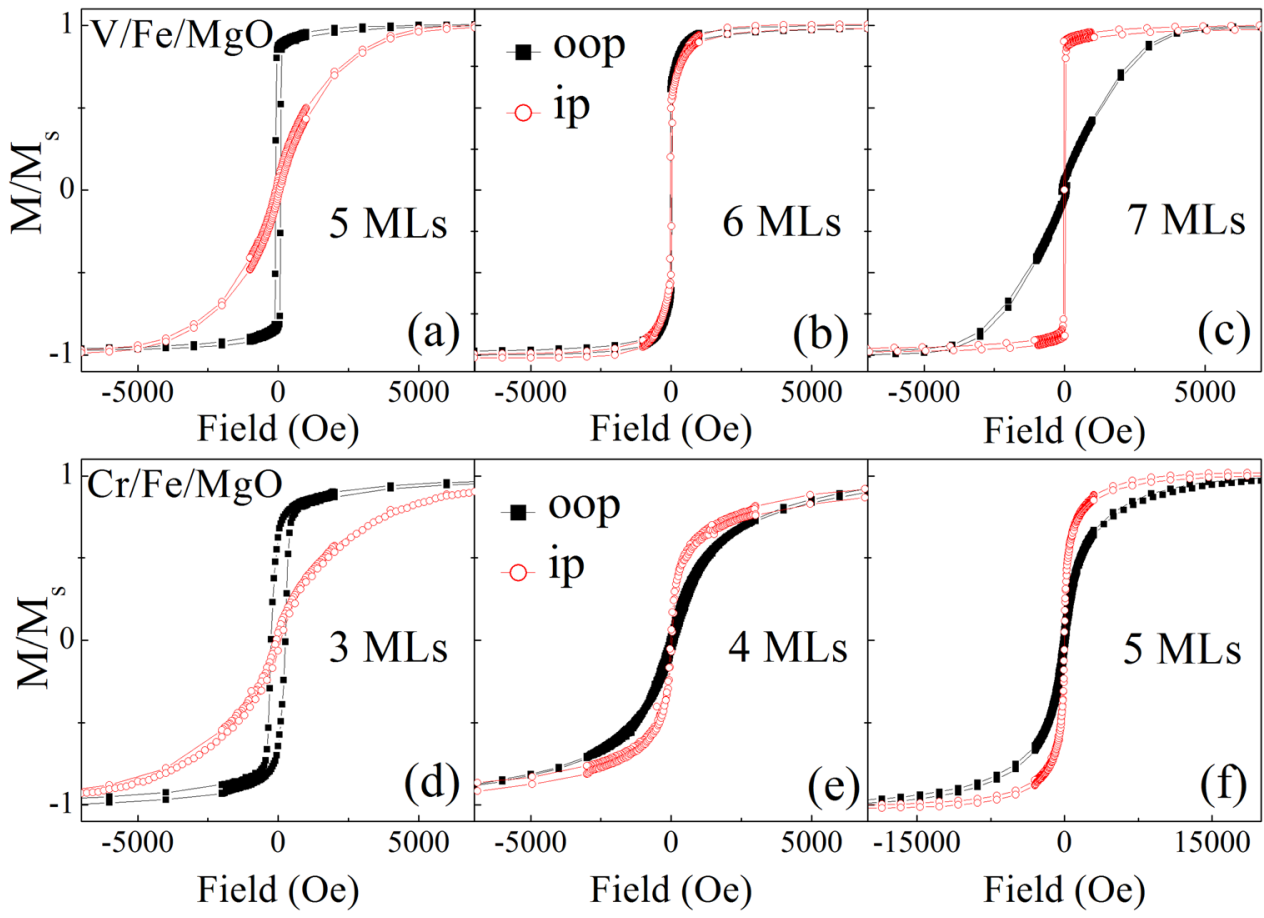

(d)

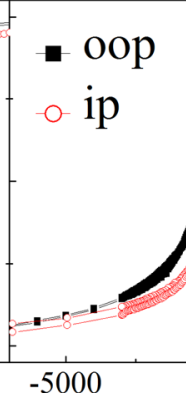

Field (Oe)
FIG. 2. Room temperature normalized magnetization as a function of magnetic field applied out-of-plane (OOP-black squares) and in the film plane (IP-red open circles), measured on $\mathrm{V} / \mathrm{Fe} / \mathrm{MgO}$ sample with $t_{\mathrm{Fe}}$ set to (a) $5 \mathrm{MLs}$, (b) $6 \mathrm{MLs}$ and (c) $7 \mathrm{MLs}$ and on $\mathrm{Cr} / \mathrm{Fe} /$ $\mathrm{MgO}$ with $\mathrm{t}_{\mathrm{Fe}}$ set to (d) 3 MLs, (e) 4 MLs and (f) 5 MLs. 


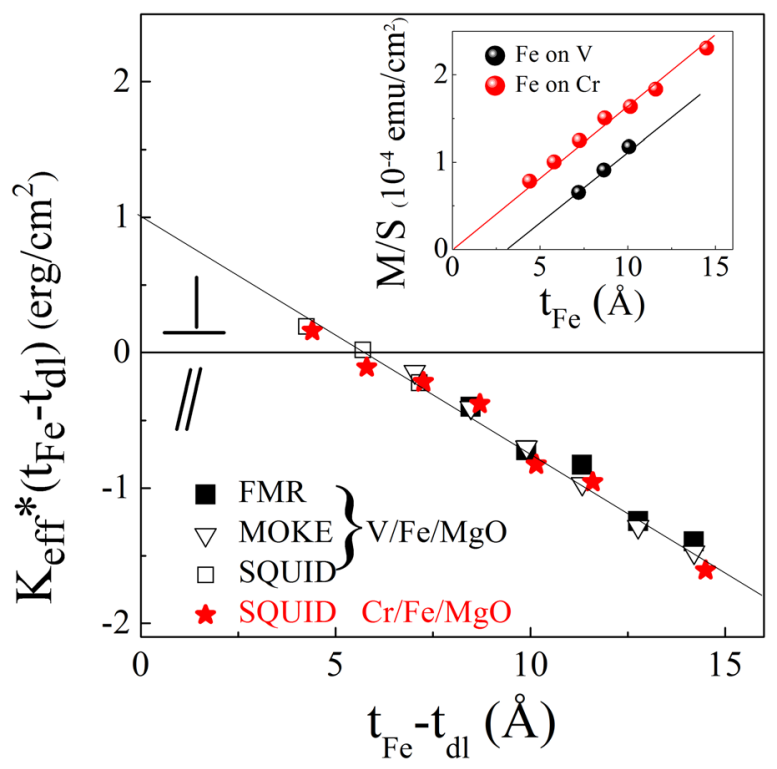

FIG. 3. Effective anisotropy constant $K_{\text {eff }}$ times $t_{\mathrm{Fe}}-t_{\mathrm{dl}}$ as a function of $\mathrm{t}_{\mathrm{Fe}} \mathrm{t}_{\mathrm{dl}}$ deduced from SQUID-VSM, FMR, and MOKE measurements at RT for both $\mathrm{V} / \mathrm{Fe} / \mathrm{MgO}$ and $\mathrm{Cr} / \mathrm{Fe} / \mathrm{MgO}$ systems. The line is a fit using Eq. (2). In inset are plotted the areal magnetization versus Fe thickness, showing that $\mathrm{t}_{\mathrm{dl}}=0$ for $\mathrm{Fe}$ on $\mathrm{Cr}$ and $\mathrm{t}_{\mathrm{dl}}=3 \AA$ for $\mathrm{Fe}$ on $\mathrm{V}$.

Fig. 3 versus the active Fe thickness corrected from the dead layers at $\mathrm{Fe} / \mathrm{V}$ interface. The unique linear variation confirms the good agreement between the results obtained from the different techniques. This behavior is usually explained writing the effective anisotropy as the sum of the different anisotropy contributions as ${ }^{16}$ (here in CGS unity)

$$
K_{\text {eff }}=K_{V}+\frac{K_{s}}{t}-2 \pi M_{s}^{2}
$$

where $\mathrm{K}_{\mathrm{v}}$ is the magnetic volume anisotropy and $\mathrm{K}_{\mathrm{s}}$ is the interfaces anisotropy acting in the Fe layer. The $-2 \pi \mathrm{M}_{\mathrm{s}}^{2}$ term comes from the shape anisotropy for a thin film. The negative sign shows that this anisotropy term tends to align the magnetization in the film plane. The thickness $t$ is the thickness of the film, but here we should take into account

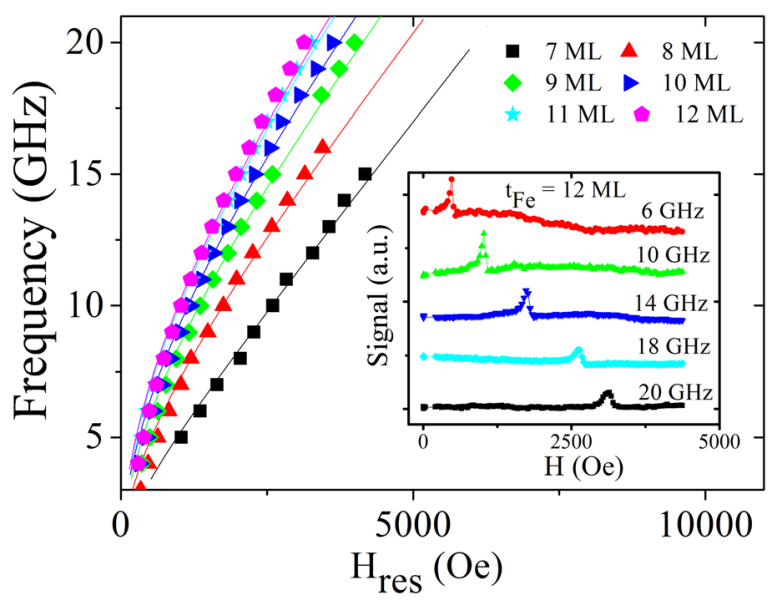

FIG. 4. FMR resonance field plotted versus DC magnetic field frequency (points) and simulations (lines) performed on $\mathrm{V} / \mathrm{Fe} / \mathrm{MgO}$ wedge with $\mathrm{t}_{\mathrm{Fe}}=7,8,9,10,11$, and 12 MLs. In inset, typical FMR responses versus field for $t_{\mathrm{Fe}}=12$ MLs for several excitation frequencies of the in-plane applied DC field. only the active magnetic layers, that is $\mathrm{t}=\mathrm{t}_{\mathrm{Fe}}-\mathrm{t}_{\mathrm{dl}}$. We thus get the linear relationship

$$
K_{e f f}\left(t_{F e}-t_{d l}\right)=\left(K_{V}-2 \pi M_{s}^{2}\right)\left(t_{F e}-t_{d l}\right)+K_{s},
$$

where $t_{d l}=2$ MLs for Fe on V and $t_{d l}=0$ for Fe on Cr. We can go further by looking in details at the volume and interface anisotropy contributions. From the slope of the experimental curve in Fig. 3, we can extract a value of the volume anisotropy $\mathrm{K}_{\mathrm{v}}-2 \pi \mathrm{M}_{\mathrm{s}}^{2}=-1.78 \times 10^{7} \mathrm{erg} / \mathrm{cm}^{3}$. By taking into account $\mathrm{M}_{\mathrm{s}}=1680 \pm 50 \mathrm{emu} / \mathrm{cm}^{3}$, the calculated shape anisotropy term is $2 \pi \mathrm{M}_{\mathrm{s}}^{2}=1.8 \times 10^{7} \mathrm{erg} / \mathrm{cm}^{3}$. Therefore, we can conclude that $\mathrm{K}_{\mathrm{V}}$ is small as compared with shape anisotropy. Indeed, volume anisotropy of cubic Fe is usually of the order of few $10^{5} \mathrm{erg} / \mathrm{cm}^{3}$ (Refs. 26 and 27) and magnetoelastic contributions are expected to be small. It should be pointed out that a magneto-elastic contribution in $\mathrm{K}_{\mathrm{v}}$ should also be taken into account in the case of strained epitaxial thin films. This contribution is very small in $\mathrm{Cr} / \mathrm{Fe} / \mathrm{MgO}$ since the $\mathrm{Cr} / \mathrm{Fe}$ misfit is around $0.6 \%$. But the misfit is much larger in $\mathrm{V} / \mathrm{Fe}$, around 5.6\%. Consequently, if the $\mathrm{Fe}$ growth on $\mathrm{V}$ is pseudomorphic, the magnetoelastic anisotropy should be non-negligible. However, we have shown in a previous study ${ }^{28}$ that the critical thickness for plastic relaxation during $\mathrm{Fe}$ growth on $\mathrm{V}$ at $\mathrm{RT}$ in our MBE system is lower than $1 \mathrm{ML}$. This means that Fe layer relaxes to its stable bcc structure, leading to small magnetoelastic anisotropy. As a consequence, the volume anisotropy originates mostly from the demagnetization term.

There are two contributions in $\mathrm{K}_{\mathrm{s}}$, one coming from the $\mathrm{V}-\mathrm{Fe}$ or $\mathrm{Cr}-\mathrm{Fe}$ interfaces, the other from the $\mathrm{Fe}-\mathrm{MgO}$ one. $\mathrm{V} /$ $\mathrm{Fe} / \mathrm{V}$ superlattices have been heavily studied in the past and in-plane anisotropy has always been reported for Fe thickness as low as 3 MLs. ${ }^{29-31}$ At low temperatures, Anisimov et al. found positive interface anisotropy of the order of few merg/ $\mathrm{cm}^{2}$ that monotonically disappears as the temperature increases to RT. ${ }^{29}$ The value of $\mathrm{K}_{\mathrm{s}}$ at $\mathrm{Cr} / \mathrm{Fe}$ interface has been measured only once in Ref. 32 as $+0.19 \mathrm{erg} / \mathrm{cm}^{2}$. To summarize, both data for $\mathrm{Fe}$ on $\mathrm{Cr}$ and on $\mathrm{V}$ in Fig. 3 are well described by Eq. (2) considering a negligible $\mathrm{K}_{\mathrm{v}}$ contribution. Therefore only $\mathrm{K}_{\mathrm{s}}$ is an unknown parameter in Eq. (2) and the accuracy on this extracted $\mathrm{K}_{\mathrm{s}}$ value is very good yielding a value of $1.0 \pm 0.1 \mathrm{erg} / \mathrm{cm}^{2}$. As the V-Fe interface anisotropy is very small, this means that this $\mathrm{K}_{\mathrm{s}}$ value comes from the $\mathrm{Fe} /$ $\mathrm{MgO}$ interface. We should however observe a slightly higher total $\mathrm{K}_{\mathrm{s}}$ in $\mathrm{Cr} / \mathrm{Fe} / \mathrm{MgO}$ since the $\mathrm{Cr} / \mathrm{Fe}$ interface contribution is not negligible when compared to the extracted $\mathrm{Fe}-\mathrm{MgO}$ one.

The extracted $\mathrm{K}_{\mathrm{s}}$ value for $\mathrm{Fe} / \mathrm{MgO}$ interface is larger than the value obtained in MBE-grown $\mathrm{Au} / \mathrm{Fe}_{\mathrm{x}} \mathrm{Co}_{1-x} / \mathrm{MgO}$ $\left(<0.5 \mathrm{erg} / \mathrm{cm}^{2}\right)^{6,16,18}$ but smaller than in tuned $\mathrm{CoFeB} / \mathrm{MgO}$ interfaces $\left(1.6 \mathrm{erg} / \mathrm{cm}^{2}\right){ }^{7}$ Such a dispersion of the $\mathrm{K}_{\mathrm{s}}$ values is in fact not surprising since $\mathrm{K}_{\mathrm{s}}$ determination by analyzing $\mathrm{K}_{\mathrm{eff}}$ may depend on subtleties that mainly come from samples preparation. This is particularly true for Fe on V here: Plotting $\mathrm{K}_{\mathrm{eff}} \mathrm{t}_{\mathrm{Fe}}$ versus $\mathrm{t}_{\mathrm{Fe}}$ (that is ignoring the dead layers) leads to a $\mathrm{K}_{\mathrm{s}}$ two times larger. Finally, we observe a $\mathrm{K}_{\mathrm{s}}$ smaller than calculated ones. ${ }^{14,15}$ One possible explanation may be the level of oxidation of $\mathrm{Fe}$ in contact with $\mathrm{MgO}$ as pointed out in Ref. 14, but we never observed such an effect in our samples. ${ }^{33,34}$ However, other defects like steps, kinks, and vacancies present 
in real systems are difficult to take into account in calculations and may decrease this interface anisotropy.

In summary, detailed analysis of magnetic properties (magnetization, effective anisotropy) allows us to enlighten the origin of PMA in $\mathrm{V} / \mathrm{Fe} / \mathrm{MgO}(001)$ and $\mathrm{Cr} / \mathrm{Fe} / \mathrm{MgO}(001)$ epitaxial layers. The Fe thickness limit for getting PMA is found to be different in both systems (below $6 \mathrm{MLs}$ in $\mathrm{V} / \mathrm{Fe} /$ $\mathrm{MgO}$ and $4 \mathrm{MLs}$ in $\mathrm{Cr} / \mathrm{Fe} / \mathrm{MgO}$ ). This is explained by the occurrence of 2 MLs magnetic dead layers in $\mathrm{Fe}$ on $\mathrm{V}$ that does not exist on Cr. For a given Fe thickness, the shape anisotropy is thus smaller in $\mathrm{V} / \mathrm{Fe}$ than in $\mathrm{Cr} / \mathrm{Fe}$ whereas the $\mathrm{Fe} / \mathrm{MgO}$ interface anisotropy is found to be similar for both systems. This work allows an accurate and robust determination of the $\mathrm{Fe} / \mathrm{MgO}$ interface anisotropy $\mathrm{K}_{\mathrm{s}}=1.0 \pm 0.1 \mathrm{erg} /$ $\mathrm{cm}^{2}\left(\mathrm{~mJ} / \mathrm{m}^{2}\right)$ responsible for PMA. Such a high $\mathrm{K}_{\mathrm{s}}$ (around 2 times larger than in the low spin-orbit prototype $\mathrm{Co} / \mathrm{Ni}(111)$ system $^{35}$ ) is very promising for further use in STT-RAM and spintronic systems.

This work was supported by the French Agence Nationale de la Recherche, ANR-10-BLANC-1005 "Friends," ANR2010-BLANC-1006 "Elecmade," and work at UCSD was supported by NSF Award \# 1002147. It was also supported by The Partner University Fund "Novel Magnetic Materials for Spin Torque Physics" as well as the European Project (OP2M FP7-IOF-2011-298060) and the Region Lorraine.

${ }^{1}$ O. Ozatay, P. G. Mather, J. U. Thiele, T. Hauet, and P. M. Braganca, "Spinbased data storage," in Nanofabrication and Devices of Comprehensive Nanoscience and Nanotechnology, edited by D. Andrews, G. Scholes, and G. Wiederrecht (Elsevier, London, 2010), Vol. 4, pp. 561-614.

${ }^{2}$ S. Mangin, D. Ravelosona, J. A. Katine, M. J. Carey, B. D. Terris, and E. E. Fullerton, Nature Mater. 5, 210 (2006).

${ }^{3}$ S. Ikeda, K. Miura, H. Yamamoto, K. Mizunuma, H. D. Gran, M. Endo, S. Kanai, J. Hayakawa, F. Matsukura, and H. Ohno, Nature Mater. 9, 721 (2010).

${ }^{4}$ J. H. Jung, S. H. Lim, and S. R. Lee, Appl. Phys. Lett. 96, 042503 (2010).

${ }^{5}$ K. Lee, J. J. Sapan, S. H. Kang, and E. E. Fullerton, J. Appl. Phys. 109, 123910 (2011).

${ }^{6}$ M. Yamanouchi, R. Koizumi, S. Ikeda, H. Sato, K. Mizunuma, K. Miura, H. D. Gan, F. Matsukura, and H. Ohno, J. Appl. Phys. 109, 07C712 (2011).

${ }^{7}$ Q. L. Ma, S. Lihama, T. Kubota, X. M. Zhang, S. Mizukami, Y. Ando, and T. Miyazaki, Appl. Phys. Lett. 101, 122414 (2012).

${ }^{8}$ M. Weisheit, S. Fähler, A. Marty, Y. Souche, C. Poinsignon, and D. Givord, Science 315, 349 (2007).

${ }^{9}$ Y. Shiota, T. Maruyama, T. Nozaki, T. Shinjo, M. Shiraishi, and Y. Suzuki, Appl. Phys. Express 2, 063001 (2009).
${ }^{10}$ T. Maruyama, Y. Shiota, T. Nozaki, K. Ohta, N. Toda, M. Mizuguchi, A. A. Tulapurka, T. Shinjo, M. Shiraishi, S. Mizukami, Y. Ando, and Y. Suzuki, Nat. Nanotech. 4, 158 (2009).

${ }^{11}$ K. Nakamura, R. Shimabukuro, Y. Fujiwara, T. Akiyama, T. Ito, and A. J. Freeman, Phys. Rev. Lett. 102, 187201 (2009).

${ }^{12}$ W.-G. Wang, M. Li, S. Hageman, and C. L. Chien, Nature Mater. 11, 64 (2012).

${ }^{13}$ M. K. Niranjan, C.-G. Duan, S. S. Jaswal, and E. Y. Tsymbal, Appl. Phys. Lett. 96, 222504 (2010).

${ }^{14}$ H. X. Yang, M. Chshiev, B. Dieny, J. H. Lee, A. Manchon, and K. H. Shin, Phys. Rev. B 84, 054401 (2011).

${ }^{15}$ K. H. He and S. J. Chen, J. Appl. Phys. 111, 07C109 (2012).

${ }^{16}$ M. T. Johnson, P. J. H. Bloemen, F. J. A. den Broeder, and J. J. de Vries, Rep. Prog. Phys. 59, 1409-1458 (1996).

${ }^{17}$ Y. Shiota, T. Nozaki, F. Bonell, S. Murakami, T. Shinjo, and Y. Suzuki, Nature Mater. 11, 39 (2012).

${ }^{18}$ T. Nozaki, Y. Shiota, M. Shiraishi, T. Shinjo, and Y. Suzuki, Appl. Phys. Lett. 96, 022506 (2010).

${ }^{19}$ A. Manchon, C. Ducruet, L. Lombard, S. Auffret, B. Rodmacq, B. Dieny, S. Pizzini, J. Vogel, V. Uhlír, M. Hochstrasser, and G. Panaccione, J. Appl. Phys. 104, 043914 (2008).

${ }^{20}$ D. Lacour, M. Hehn, M. Alnot, F. Montaigne, F. Greullet, G. Lengaigne, O. Lenoble, S. Robert, and A. Schuhl, Appl. Phys. Lett. 90, 192506 (2007).

${ }^{21}$ F. Bonell, S. Murakami, Y. Shiota, T. Nozaki, T. Shinjo, and Y. Suzuki, Appl. Phys. Lett. 98, 232510 (2011).

${ }^{22}$ J. Izquierdo, R. Robles, A. Vega, M. Talanana, and C. Demangeat, Phys. Rev. B 64, 060404(R) (2001).

${ }^{23}$ M. Sicot, S. Andrieu, P. Turban, Y. Fagot-Revurat, H. Cercellier, A. Tagliaferri, C. De Nadai, N. B. Brookes, F. Bertran, and F. Fortuna, Phys. Rev. B 68, 184406 (2003).

${ }^{24}$ F. Dulot, P. Turban, B. Kierren, J. Eugène, M. Alnot, and S. Andrieu, Surf. Sci. 473, 172 (2001).

${ }^{25}$ C. Kittel, Phys. Rev. 73, 155 (1948).

${ }^{26}$ C. D. Graham, Phys. Rev. 112, 1117 (1958).

${ }^{27}$ D. Sander, J. Phys.: Condens. Matter 16, 603 (2004).

${ }^{28}$ P. Turban, L. Hennet, and S. Andrieu, Surf. Sci. 446, 241 (2000).

${ }^{29}$ A. N. Anisimov, M. Farle, P. Poulopoulos, W. Platow, K. Baberschke, P. Isberg, R. Wäppling, A. M. N. Niklasson, and O. Eriksson, Phys. Rev. Lett. 82, 2390 (1999).

${ }^{30}$ H. Fritzche, T. Nawrath, H. Maletta, and H. Lauter, Physica B 241-243, 707 (1997).

${ }^{31}$ A. Broddefalka P. Nordblada, P. Blomqvist, P. Isberg, R. Wappling, O. Le Bacq, and O. Eriksson, J. Magn. Magn. Mater. 241, 260 (2002).

${ }^{32}$ A. Macedo Texeira, C. A. Ramos, A. A. R. Fernandes, and E. E. Fullerton, J. Magn. Magn. Mater. 226-230(2), 1788 (2001).

${ }^{33}$ V. Serin, S. Andrieu, R. Serra, F. Bonell, C. Tiusan, L. Calmels, M. Varela, S. J. Pennycook, E. Snoeck, M. Walls, and C. Colliex, Phys. Rev. B 79, 144413 (2009).

${ }^{34}$ F. Bonell, S. Andrieu, A. M. Bataille, C. Tiusan, and G. Lengaigne, Phys. Rev. B 79, 224405 (2009).

${ }^{35}$ M. Gottwald, S. Andrieu, F. Gimbert, E. Shipton, L. Calmels, C. Magen, E. Snoeck, M. Liberati, T. Hauet, E. Arenholz, S. Mangin, and E. E. Fullerton, Phys. Rev. B 86, 014425 (2012), and references therein. 